\title{
The Effect of an Increase in Systemic Arterial Pressure in the Newborn with Right Ventricular Hypertension
}

\author{
JAQUES BELIK, KEN BARON, AND R. BRUCE LIGHT \\ Departments of Pediatrics, Anesthesia, and Medicine, University of Manitoba, Winnipeg, Manitoba, Canada
}

\begin{abstract}
To evaluate the effect of an elevation in systemic arterial pressure upon pulmonary blood flow and arterial oxygenation during right ventricular hypertension (RVH), we acutely studied 13 1-d-old piglets. Catheters were positioned in the pulmonary artery, both atria, and the aorta for hemodynamic measurements. An electromagnetic probe was positioned in the main pulmonary artery for pulmonary blood flow measurement. Systemic and regional blood flow were measured with the radiolabeled microsphere technique. A balloon-mounted catheter was advanced in the aorta and maintained at the lower thoracic level. After induction of RVH (pulmonary artery banding), a significant decrease in arterial $\mathrm{O}_{2}$ pressure from $54.4 \pm$ 1.6 to $10.6 \pm 0.4 \mathrm{kPa}(p<0.01)$, a $30 \%$ reduction in systemic arterial pressure, and a $44 \%$ decrease in pulmonary blood flow were observed. During RVH, partial inflation of the aortic balloon to restore the systemic arterial pressure to its initial value led to an increase in arterial $\mathrm{O}_{2}$ pressure to $23.5 \pm 3.1 \mathrm{kPa}(p<0.01)$. Full inflation of the balloon further increased the arterial $\mathrm{O}_{2}$ pressure to 32.6 $\pm 2.9 \mathrm{kPa}(p<0.01)$. Aortic balloon inflation increased pulmonary blood flow in 11 and systemic $\mathrm{O}_{2}$ delivery in nine of the 13 animals. RVH was associated with a significant increase in cerebral and right ventricular myocardial free-wall blood flow and a decrease in renal and bowel blood flow and $\mathrm{O}_{2}$ delivery $(p<0.01)$. Aortic balloon inflation during RVH did not change either the cerebral or myocardial free-wall blood flow, but further significantly decreased renal and bowel blood flow and $\mathrm{O}_{2}$ delivery. In conclusion, an elevation in systemic arterial pressure significantly reduces foramen ovale shunt and increases pulmonary blood flow and systemic $\mathrm{O}_{2}$ delivery in the newborn pig with RVH. This finding may prove useful in the clinical management of hypoxemic infants with persistent pulmonary hypertension syndrome. (Pediatr Res 28: 603-608, 1990)
\end{abstract}

\section{Abbreviations}

RVH, right ventricular hypertension

$\mathrm{Q}_{\mathrm{S}} / \mathrm{Q}_{\mathrm{T}}$, shunt fraction

$\mathrm{DO}_{2}$, systemic oxygen delivery

$P_{S A}$, systemic arterial pressure

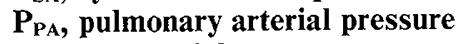

$P_{\mathrm{RA}}$, right atrial pressure

$P_{L A}$, left atrial pressure

$\dot{Q}_{\mathrm{P}}$, pulmonary blood flow

$\hat{Q}_{S}$, systemic cardiac output

Received April 19, 1990; accepted July 6, 1990.

Correspondence: Jaques Belik, Room WR 004, 735 Notre Dame Ave., Winnipeg, Manitoba, Canada R3E 0L8.

Supported by grants from the Children's Hospital Research Foundation of Winnipeg.
PPHN, persistent pulmonary hypertension syndrome $\mathrm{PaO}_{2}$, arterial $\mathrm{O}_{2}$ pressure

In the newborn pig, we have previously shown that RVH is associated with a significant decrease in $\mathrm{P}_{\mathrm{SA}}$ and cardiac output $(1,2)$. The factors responsible for the reduction in cardiac output during RVH are presently unclear, but previously reported data suggest that the reduction is related to the changes in $P_{S A}(3-6)$.

Meadow et al. (3) reported that after group B streptococcusinduced pulmonary hypertension in the piglet, a significant increase in $\dot{Q}_{P}$ can be achieved by elevating the $\mathrm{P}_{\mathrm{SA}}$. Although not evaluated in their experimental animals, Meadow et al. also suggested that a selective elevation of the $\mathrm{P}_{\mathrm{SA}}$ during pulmonary hypertension could also impede right to left shunt at the foramen ovale and thus improve oxygenation (3). Furthermore, in adult animals with RVH and decreased $\dot{Q}_{\mathrm{P}}$, an elevation in $\mathrm{P}_{\mathrm{SA}}$ increases cardiac output (4-6).

In infants, the PPHN syndrome is associated with hypoxemia related not only to the decreased $\dot{\mathrm{Q}}_{\mathrm{P}}$, but also to the magnitude of the right to left shunt across the fetal channels. Limited therapeutic means are presently available to obtain either an increase in $\dot{Q}_{P}$ or a decrease in the right to left shunt in infants with the severe forms of this syndrome. The effect of an increase in $\mathrm{P}_{\mathrm{SA}}$ in the newborn with $\mathrm{RVH}$ and right to left shunt across the fetal channels has not been previously evaluated.

Therefore, the purpose of our study was to determine the effect of an increase in $\mathrm{P}_{\mathrm{SA}}$ upon $\dot{\mathrm{Q}}_{\mathrm{P}}$ and arterial oxygenation in the 1d-old pig with RVH. Our newborn pig RVH model is most suitable for this purpose because the foramen ovale is patent in the 1-d-old animal and a right to left shunt through this fetal channel is observed during $\mathrm{RVH}(1,2)$.

To avoid any further increase in the pulmonary vascular resistance, we inflated a balloon in the aorta as a means to increase the $\mathrm{P}_{\mathrm{SA}}$ during $\mathrm{RVH}$. The central hemodynamics changes, as well as the pulmonary, systemic, myocardial, and regional blood flow, were measured before and after balloon inflation to assess its effect upon shunt fraction, cardiac output, organ blood flow, and oxygen delivery during RVH.

\section{MATERIALS AND METHODS}

Surgical preparation. Thirteen pigiets with a mean weight of $2.3 \pm 0.1 \mathrm{~kg}$ and less than $24 \mathrm{~h}$ of age were studied under this protocol. On the day of the experiment, the animals were separated from the sow and prepared for study after receiving fentanyl citrate $(50 \mu \mathrm{g} / \mathrm{kg}$ i.v. $)$ and a single induction dose of ketamine $(10 \mathrm{mg} / \mathrm{kg}$ intramuscular). Initially, the trachea was cannulated and the animals were connected to an infant mechanical ventilator (BabyBird, Bird Corporation, Palm Springs, CA). Pancuronium bromide $(0.2 \mathrm{mg} / \mathrm{kg}$ i.v. $)$ was administered, and the 
ventilator settings were adjusted to ensure normocapnia. The details of the surgical preparation have been previously described (1). Briefly, a 4 Fr catheter, with an incorporated oxygen electrode, was advanced into the abdominal aorta through the femoral artery and attached to a monitor to continuously read in vivo $\mathrm{PaO}_{2}$ (Neochat Neonatal Oxygen Monitoring System, Biomedical Sensors Inc., Bucks, England). A $5 \mathrm{Fr}$ double-lumen Behrmán catheter was introduced through the other femoral artery and advanced to the lower thoracic level of the aorta at a location immediately distal to the previous catheter (Fig. 1). In this manner, aortic pressure proximal to the balloon was monitored via the Behrman catheter port, whereas the pressure distal to the balloon was monitored by the other aortic catheter. After a left lateral thoracotomy and ductus arteriosus ligation, a $5 \mathrm{Fr}$ catheter was advanced into the main pulmonary artery by direct puncture immediately distal to the pulmonic valve and secured by means of a purse string to the vessel wall. After careful dissection of the pulmonary artery, a silk band was placed distal to the ductus arteriosus and connected to a mechanical device that allowed for progressive vessel occlusion. A precalibrated electromagnetic flow probe was placed around the main pulmonary artery adjacent to the pressure catheter [Carolina Medical Electronics, Inc. (King, NC) flowmeter and probe]. Finally, left and right atrial catheters were inserted, the former via the left atrial appendage and the latter by femoral venous access. The left chest incision was approximated and covered with a plastic sheet and care was taken to completely reexpand the left lung after completion of the surgery.

For the duration of the experiment, the animals were ventilated with oxygen $\left(\mathrm{FiO}_{2}=1\right)$ to ensure normoxemia after the induction of right to left shunt. Positive end expiratory pressure $(0.3 \mathrm{kPa})$ was added to the ventilator to maintain lung inflation and was increased to $1.3 \mathrm{kPa}$ for a few seconds on a regular basis during the experiment to prevent any lung atelectasis. The peak inspiratory pressure was set at $1.6-2 \mathrm{kPa}$ and maintained constant during the experiment.

Rectal temperature was monitored continuously (Yellow Springs telethermometer, Yellow Springs Instruments Co., Yellow Springs, $\mathrm{OH}$ ), and maintained at $38.5 \pm 0.5^{\circ} \mathrm{C}$ by means of an overhead electric heating device. End tidal $\mathrm{CO}_{2}$ concentration was measured continuously at the endotracheal tube (Beckman OM-11) and the ventilator rate was adjusted to maintain the arterial $\mathrm{CO}_{2}$ pressure constant. The catheters were connected to Gould pressure transducers (Gould Inc., Oxnard, CA) to allow for continuous recording of $\mathrm{P}_{\mathrm{SA}}$ proximal and distal to the aortic balloon, $\mathrm{P}_{\mathrm{PA}}, \mathrm{P}_{\mathrm{RA}}, \mathrm{P}_{\mathrm{LA}}, \dot{\mathrm{Q}}_{\mathrm{P}}$, rectal temperature, and $\mathrm{PaO}_{2}$. Mean pressures were obtained by electrical integration, and the heart rate was extracted from the pressure tracing.

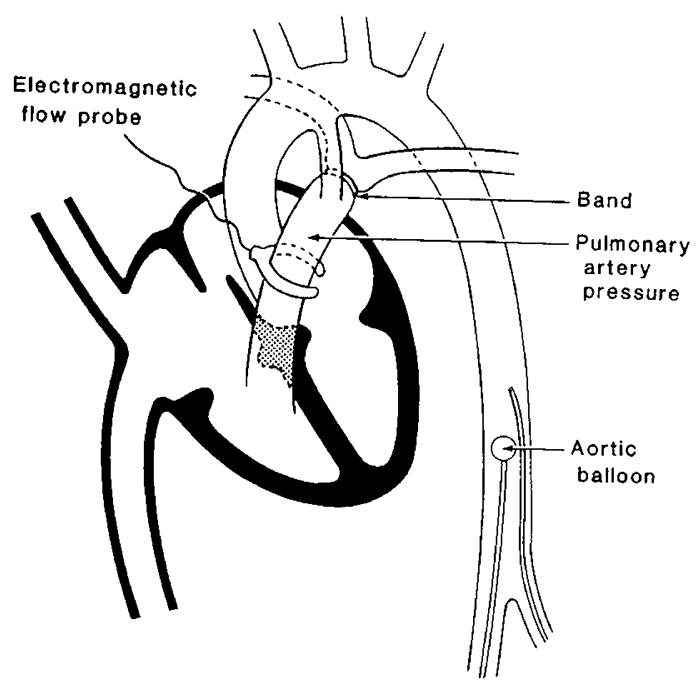

Fig. 1. Surgical preparation. See text for details.
The animals were allowed a stabilization period of at least $1 \mathrm{~h}$ before any experimentation was initiated. Anesthesia was maintained by a continuous fentanyl citrate i.v. administration (10 $\mu \mathrm{g} / \mathrm{kg} / \mathrm{h})$, and pancuronium bromide $(0.05 \mathrm{mg} / \mathrm{kg}$ i.v. $)$ was repeated when spontaneous breathing was noted. A solution of $5 \%$ glucose and normal saline was infused at $6 \mathrm{~mL} / \mathrm{kg} / \mathrm{h}$ to prevent dehydration and hypoglycemia, and a $4.2 \%$ sodium bicarbonate solution was administered i.v. when necessary for metabolic acidosis.

Arterial blood gas measurements were made using a microelectrode technique $(0.2 \mathrm{~mL}$ of blood) on a model ABL-3 Radiometer blood gases analyzer (Radiometer, Copenhagen, Denmark). Blood oxygen saturation and $\mathrm{Hb}$ determination were measured by micro sample $(0.1 \mathrm{~mL})$ in a model OSM-2 Radiometer. The arterial and mixed-venous oxygen content were calculated according to the standard formula: blood $\mathrm{O}_{2}$ content $=1.36 \times \mathrm{Hb} \times \mathrm{SaO}_{2}+\mathrm{PaO}_{2} \times 0.003$ where $\mathrm{Hb}=\mathrm{Hb}$ concentration and $\mathrm{SaO}_{2}=$ blood oxygen saturation. These data were used to calculate $\mathrm{Q}_{\mathrm{S}} / \mathrm{Q}_{\mathrm{T}}$ according to the following formula:

$$
\mathrm{Q}_{\mathrm{S}} / \mathrm{Q}_{\mathrm{T}}=\frac{\mathrm{CcO}_{2}-\mathrm{CaO}_{2}}{\mathrm{CcO}_{2}-\mathrm{CvO}_{2}}
$$

where $\mathrm{CaO}_{2}$ is arterial oxygen content, $\mathrm{CvO}_{2}$ is mixed venous oxygen content, and $\mathrm{CcO}_{2}$ is the oxygen content of blood equilibrated with ideal alveolar gas, calculated from the $\mathrm{O}_{2}$ content equation above using an alveolar $\mathrm{PO}_{2}$ taken from the alveolar gas equation. $\dot{\mathrm{DO}}_{2}$ was calculated as $\dot{\mathrm{Q}}_{\mathrm{S}} \times \mathrm{CaO}_{2}$. Regional $\mathrm{O}_{2}$ delivery was calculated as the organ blood flow $\times \mathrm{CaO}_{2}$.

Systemic vascular resistance was calculated as $\left(\mathrm{P}_{\mathrm{SA}}-\mathrm{P}_{\mathrm{RA}}\right) / \dot{\mathrm{Q}}_{\mathrm{S}}$. In six of the animals, $\dot{\mathrm{Q}}_{S}$ was derived from the tracer microspheres injection data (see description below); in all others, it was calculated according to the following formula:

$$
\dot{\mathrm{Q}}_{\mathrm{S}}=\left[\dot{\mathrm{Q}}_{\mathrm{P}} /\left(1-\mathrm{Q}_{\mathrm{S}} / \mathrm{Q}_{\mathrm{T}}\right)\right]
$$

The pulmonary vascular resistance was chosen to estimate the right ventricular afterload and was calculated as $\left(\mathrm{P}_{\mathrm{PA}_{\mathrm{A}}}-\mathrm{P}_{\mathrm{LA}}\right) / \dot{\mathrm{Q}}_{\mathrm{P}}$.

Measurement of organ blood flow. Blood flow to the different organs was measured with the tracer microsphere technique in six of the animals. Microspheres $(15 \pm 1 \mu \mathrm{m})$ labeled with ${ }^{141} \mathrm{Ce}$, ${ }^{85} \mathrm{Sr}$, or ${ }^{46} \mathrm{Sc}(3 \mathrm{M}$, St. Paul, MN) were used. Stock solutions were sonicated for $5 \mathrm{~min}$ and shaken vigorously on a vortex mixer for $2-5$ min. Approximately $0.7-1.2 \times 10^{6}$ microspheres were placed into specially prepared injection vials and shaken again on a vortex mixer before injection. The contents of the injection vial were flushed into the left atrium over a period of 15-30 s. Reference arterial blood was withdrawn from the most proximal aortic catheter for $10 \mathrm{~s}$ before and during and for $60 \mathrm{~s}$ after the microsphere injection at a rate of $1.03 \mathrm{~mL} / \mathrm{min}$.

At the end of the experiment, the animals were killed by an i.v. injection of concentrated potassium chloride, and the brain, heart, kidneys, and bowel (duodenum, small and large bowel) were removed. The heart was further dissected to separate the right and left ventricular free-wall myocardium. The tissues were weighed and placed into counting vials. The bowel and remaining carcass were carbonized and a weighed sample also placed into counting vials as were the reference blood samples. Counting vials were filled to a height of less than $2.5 \mathrm{~cm}$ to minimize geometrical counting error.

Tissue and reference blood samples were counted for $3 \mathrm{~min}$ with a multichannel gamma counter (Compugama, LKB-Produkter AB, Bromma, Sweden). Nuclide separation was performed using standard methods for differential spectrometry, as we have previously described (2). Left ventricular output was calculated by entering the total animal activity and body weight in $\mathrm{kg}$ in the above formula. Bowel flows were expressed as $\mathrm{mL}$. $\min ^{-1} \cdot 100 \mathrm{~g}^{-1}$ of wet tissue weight.

Experimental procedure. Initially, baseline measurements of $\mathrm{P}_{\mathrm{PA}}$, proximal and distal $\mathrm{P}_{\mathrm{SA}}, \mathrm{P}_{\mathrm{RA}}, \mathrm{P}_{\mathrm{LA}}$, and $\dot{\mathrm{Q}}_{\mathrm{P}}$ were obtained. $\mathrm{A}$ left atrial radionuclide microsphere injection was performed to 
measure $\dot{\mathrm{Q}}_{S}$ and regional blood flow distribution. After the initial measurements, the pulmonary artery was progressively constricted until the $\mathrm{PaO}_{2}$ fell below $13.3 \mathrm{kPa}$, indicating the presence of significant right to left foramen ovale shunting, herein labeled as RVH. Measurements similar to the initial values were repeated during RVH and the aortic balloon was inflated until the mean $\mathrm{P}_{\mathrm{SA}}$ proximal to the balloon was increased to a level similar to the initial pre-RVH $\mathrm{P}_{S A}$ (partial balloon inflation). Thereafter, the aortic balloon was further inflated until the distal $P_{\mathrm{SA}}$ was no longer pulsatile (full balloon inflation). Measurements similar to the initial ones were repeated during partial and full balloon inflation. The balloon was then completely deflated and the experimental variables were again recorded. Finally, the pulmonary artery band was released and a last set of measurements was obtained (final).

Arterial and venous blood gases, oxygen saturation, and $\mathrm{Hb}$ were obtained with each set of measurements. Only three radiolabeled microspheres injections were performed: 1 ) initial; 2) during RVH; and 3) during partial aortic balloon inflation.

This protocol was approved by the Ethics Committee on Animal Experimentation of the University of Manitoba.

Statistical analysis. All data are reported as mean \pm SEM. Analysis of variance for repeat measurements was used to evaluate any variable over time. Multiple comparisons were done by the Newman-Keul's post hoc test. Stepwise multiple regression analysis was used to evaluate the contribution of different variables upon the changes in $\dot{\mathrm{Q}}_{\mathrm{p}}$ and $\dot{\mathrm{DO}}_{2}$. The least square method was used to derive the linear regression and correlation coefficients between $\dot{\mathrm{Q}}_{\mathrm{P}}, \dot{\mathrm{D}} \mathrm{O}_{2}$, and $\mathrm{O}_{2}$ content. A comparison between the measured cardiac output by the tracer microspheres technique and the calculated value of $\dot{\mathrm{Q}}_{\mathrm{s}}$ was done by the paired $t$ test. A $p<0.05$ was considered significant.

\section{RESULTS}

Hemodynamic changes. A significant increase in the foramen ovale right to left shunt was seen after a two-fold increase in $\mathrm{P}_{\mathrm{PA}}$ and a $100 \%$ increase in PRA. RVH induced an average 30\% decrease in $\mathrm{P}_{\mathrm{SA}}(p<0.01)$ without a significant change in the systemic vascular resistance. The $\mathrm{P}_{\mathrm{RA}}$ increased during $\mathrm{RVH}$ $(p<0.01)$ but never exceeded the $\mathrm{P}_{\mathrm{LA}}$ by analysis of variance (Fig. 2).

Partial inflation of the aortic balloon to increase the proximal aortic blood pressure to a value similar to the initial $\mathrm{P}_{\mathrm{SA}}$ led to a $40 \%$ increase in the calculated systemic vascular resistance proximal to the balloon $(p<0.01)$ without a change in the $\mathrm{P}_{\mathrm{PA}}, \mathrm{P}_{\mathrm{RA}}$, and $\mathrm{P}_{\mathrm{LA}}$. Maximal inflation of the balloon led to a further $30 \%$ increase in the calculated systemic vascular resistance $(p<0.01)$, also without any associated change in the pulmonary or atrial pressures. Deflation of the aortic balloon restored the proximal and distal aortic pressures to their preinflation levels, and subsequent release of the pulmonary arterial band was associated with a decrease in $\mathrm{P}_{\mathrm{PA}}$ and a return of the $\mathrm{P}_{\mathrm{SA}}$ to levels comparable to the initial ones (Fig. 2).

The right to left shunt induced by RVH led to a decrease in $\mathrm{PaO}_{2}$ from $54.4 \pm 1.6$ to $10.6 \pm 0.4 \mathrm{kPa}(p<0.01)$ and an increase in the calculated $\mathrm{Q}_{\mathrm{S}} / \mathrm{Q}_{\mathrm{T}}$ from $10.8 \pm 1.0$ to $27.1 \pm 1.0 \%$ $(p<0.01)$ (Fig. 3).

Partial aortic balloon inflation significantly reduced the foramen ovale shunt as evidenced by the two-fold increase in $\mathrm{PaO}_{2}$ $(p<0.01)$. In addition, complete aortic occlusion was associated with a further significant increase in $\mathrm{PaO}_{2}(p<0.01)$. This improvement in oxygenation was entirely reversed after the aortic balloon deflation. Similarly, the $\mathrm{Q}_{\mathrm{S}} / \mathrm{Q}_{\mathrm{T}}$ significantly decreased by $30 \%$ with partial balloon inflation $(p<0.01)$, but no further change was observed during full aortic balloon inflation (Fig. 3).

The other arterial blood gas results and $\mathrm{Hb}$ concentration for all conditions are illustrated in Table 1 . The $\mathrm{pH}$ and calculated serum bicarbonate significantly decreased $(p<0.05)$ during
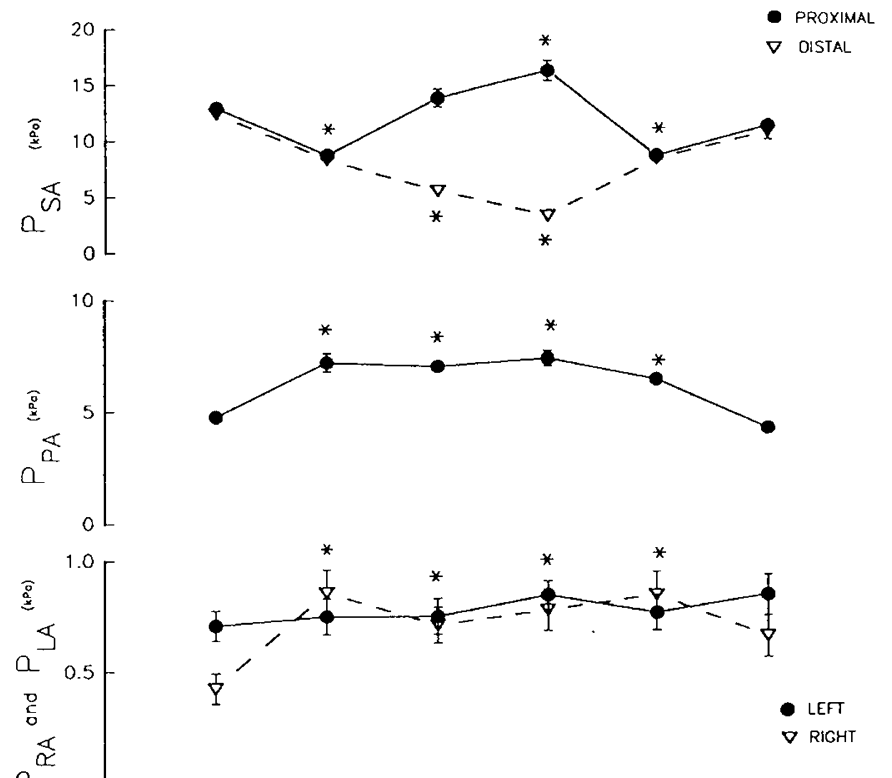

LEFT

a 0.0

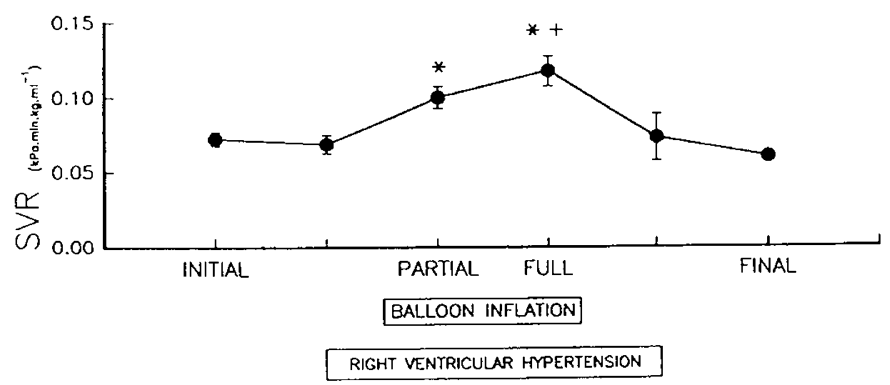

Fig. 2. $\mathrm{P}_{\mathrm{SA}}$ proximal and distal to the aortic balloon, $\mathrm{P}_{\mathrm{PA}}, \mathrm{P}_{\mathrm{RA}}, \mathrm{P}_{\mathrm{LA}}$, and systemic vascular resistance initially (INITIAL), during RVH with partial and full aortic balloon inflation, and after release of the pulmonary vessel occluder $(F I N A L) .^{*} p<0.01$ as compared with the initial values; $+p<0.01$ as compared with partial balloon inflation values by analysis of variance $(n=13)$.

$\mathrm{RVH}$ and aortic balloon inflation indicating the presence of metabolic acidosis. Also, a small but significant decrease in the $\mathrm{Hb}$ concentration $(p<0.05)$, secondary to blood letting, was observed by analysis of variance during the experiment.

$\mathrm{RVH}$ was associated with a decrease in $\dot{\mathrm{Q}}_{\mathrm{P}}$ from $181 \pm 9$ to $108 \pm 11 \mathrm{~mL} \cdot \mathrm{min}^{-1} \cdot \mathrm{kg}^{-1}$, a reduction in $\mathrm{Q}_{\mathrm{S}}$ from $176 \pm 9$ to $131 \pm 14 \mathrm{~mL} \cdot \min ^{-1} \cdot \mathrm{kg}^{-1}(p<0.01)$, and a decrease in $\mathrm{DO}_{2}$ from $21.4 \pm 1.7$ to $13.2 \pm 1.6 \mathrm{~mL} \cdot \mathrm{min}^{-1} \cdot \mathrm{kg}^{-1}(p<0.01)$. The subsequent increase in $\mathrm{P}_{\mathrm{SA}}$ induced by the inflation of the aortic balloon had a significant effect upon $\dot{\mathrm{Q}}_{\mathrm{P}}$ and $\dot{\mathrm{DO}}_{2}$.

In 11 of the 13 animals, either partial or full aortic balloon inflation led to an increase in $\dot{Q}_{\mathrm{p}}$. A similar pattern was observed for the $\dot{\mathrm{D}} \mathrm{O}_{2}$, where either partial or full aortic balloon inflation led to an increase in this parameter in nine of the 13 animals (Fig. 4). On average, partial aortic balloon inflation increased the $\dot{Q}_{\mathrm{P}}$ by $6 \pm 6 \%$ and $\dot{\mathrm{DO}}_{2}$ by $8 \pm 7 \%$, whereas full inflation was associated with a greater but not statistically significant increase of $17 \pm 7$ and $16 \pm 7 \%$ in $\dot{\mathrm{Q}}_{\mathrm{P}}$ and $\dot{\mathrm{DO}}_{2}$, respectively. Deflation of the balloon immediately reversed these changes, and subsequent release of the pulmonary artery band resulted in pulmonary and systemic blood flow values similar to the initial ones.

The percentage change in $\dot{\mathrm{DO}}_{2}$ after balloon inflation was mostly related to the magnitude of the associated change in $\dot{\mathrm{Q}}_{\mathrm{P}}$ $\left(R^{2}=0.90 ; p<0.01\right)$, whereas the $\mathrm{O}_{2}$ content changes correlated poorly with the $\mathrm{DO}_{2}$ by the least square method $\left(R^{2}=0.05 p=\right.$ NS) (Fig. 5). To evaluate the factors responsible for the presence and magnitude of increase in $\dot{Q}_{p}$ during $\mathrm{RVH}$, we analyzed the 

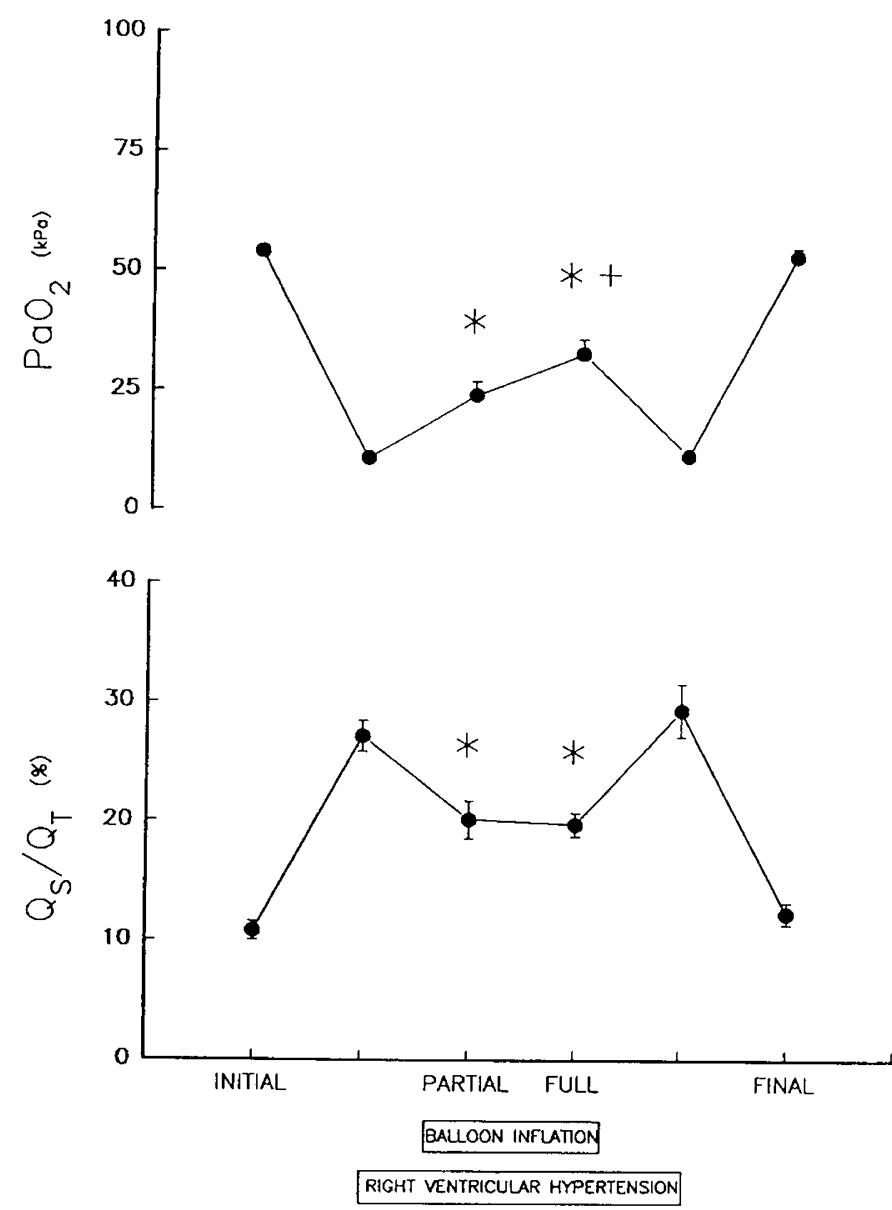

Fig. 3. Arterial oxygenation and shunt fraction. ${ }^{*} p<0.01$ as compared with values during $\mathrm{RVH}$ before aortic balloon inflation; $+p<$ 0.01 as compared with partial aortic balloon inflation values by analysis of variance $(n=13)$.

Table 1. Arterial blood gases, $\mathrm{pH}, \mathrm{Hb}$ concentration and calculated serum bicarbonate $\left(\mathrm{HCO}_{3}\right)$ before and after $\mathrm{RVH}$ and during aortic balloon inflation (mean $\pm S E M ; n=13$ )

\begin{tabular}{ccccc}
\hline & \multicolumn{3}{c}{$\begin{array}{c}\mathrm{HCO}_{3} \\
(\mathrm{mM} /\end{array}$} \\
& $\mathrm{pH}$ & $(\mathrm{kPa})$ & $\mathrm{L})$ & $\mathrm{Hb}(\mathrm{g} \%)$ \\
\hline Initial RVH & $7.40 \pm 0.01$ & $4.8 \pm 0.1$ & $23 \pm 1$ & $8.7 \pm 0.4$ \\
Balloon off & $7.31 \pm 0.02^{*}$ & $5.2 \pm 0.3$ & $19 \pm 1^{*}$ & $8.4 \pm 0.5$ \\
Balloon partial & $7.32 \pm 0.02^{*}$ & $4.7 \pm 0.3$ & $18 \pm 1^{*}$ & $7.5 \pm 0.5^{*} \dagger$ \\
Balloon full & $7.34 \pm 0.02^{*}$ & $4.1 \pm 0.3$ & $17 \pm 0^{*}$ & $7.5 \pm 0.4^{*} \dagger$ \\
Balloon off & $7.25 \pm 0.02^{*}$ & $5.3 \pm 0.3$ & $17 \pm 1^{*}$ & $7.6 \pm 0.4^{*}$ \\
Final & $7.36 \pm 0.02^{*}$ & $4.7 \pm 0.1$ & $19 \pm 1^{*}$ & $7.2 \pm 0.4^{*}$ \\
\hline
\end{tabular}

$* p<0.05$ as compared with initial values.

$\dagger p<0.05$ as compared with pulmonary hypertension with balloon.

percentage change of all measured hemodynamic variables during aortic balloon inflation by stepwise multiple regression statistics. Only the percentage change in $\mathrm{P}_{\mathrm{SA}}$ and $\mathrm{P}_{\mathrm{PA}}$ was significantly associated with the changes in $\dot{\mathrm{Q}}_{\mathrm{P}}$ during aortic balloon inflation $\left(R^{2}=0.48\right.$ and $R^{2}=0.4$, respectively; $\left.p<0.01\right)$. The changes in $\dot{Q}_{\mathrm{P}}$ with the aortic balloon were not related to either the values before or the percentage changes in $\mathrm{PaO}_{2}$ and atrial pressures during balloon inflation.

Regional blood flow measurements. RVH was associated with a significant reduction in renal and bowel blood flow and an increase in cerebral blood flow $(p<0.01)$. Partial aortic balloon inflation led to a further significant reduction in renal and bowel blood flow from the RVH levels $(p<0.01)$ and a significant increase in myocardial blood flow as compared with the initial
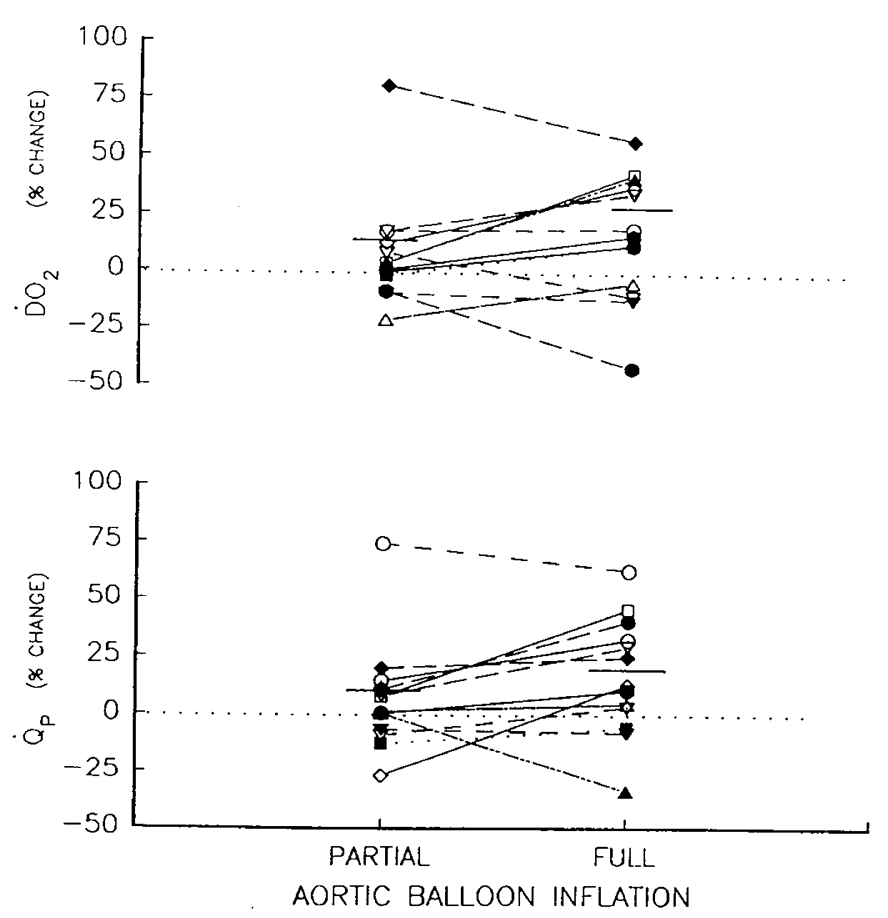

Fig. 4. $\dot{\mathrm{Q}}_{\mathrm{P}}$ and $\dot{\mathrm{DO}}_{2}$ during partial and full balloon inflation as percentage change from preinflation values during RVH. Each animal is represented by a different symbol and line and the mean percentage change is illustrated as a wider bar $(n=13)$.
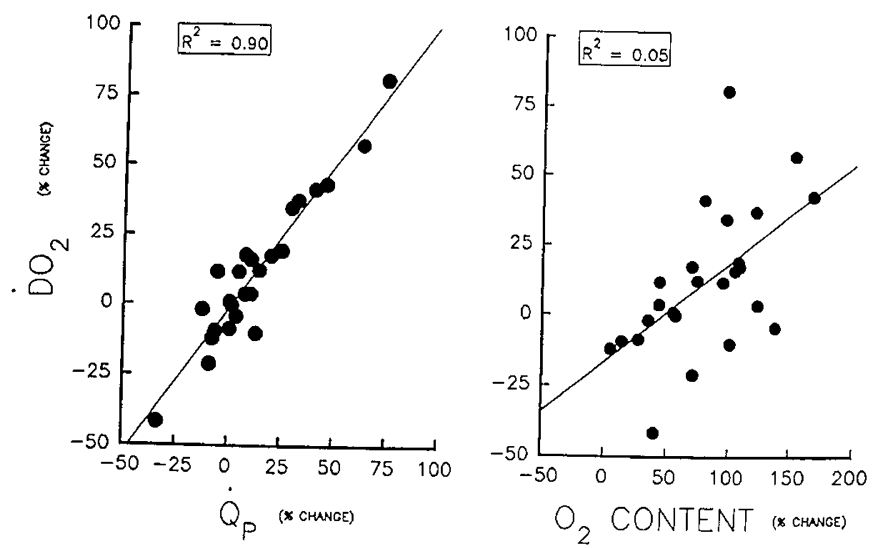

Fig. 5. Correlation between percentage changes in total $\mathrm{DO}_{2}$ during partial and full aortic balloon inflation $v s \dot{\mathrm{Q}}_{\mathrm{p}}$ and $\mathrm{O}_{2}$ content from the preinflation $\mathrm{RVH}$ values. Note that $90 \%$ of the changes in $\mathrm{DO}_{2}$ are explained by the changes in $\dot{Q}_{\mathrm{P}}\left(R^{2}=0.90\right)$.

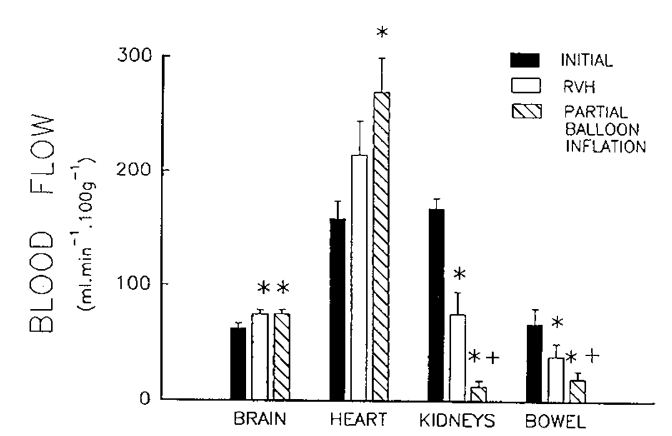

Fig. 6. Regional blood flow initially, during $\mathrm{RVH}$, and after partial inflation of the aortic balloon. $* p<0.01$ as compared with the initial values; $+p<0.01$ as compared with the RVH values by analysis of variance $(n=6)$. 


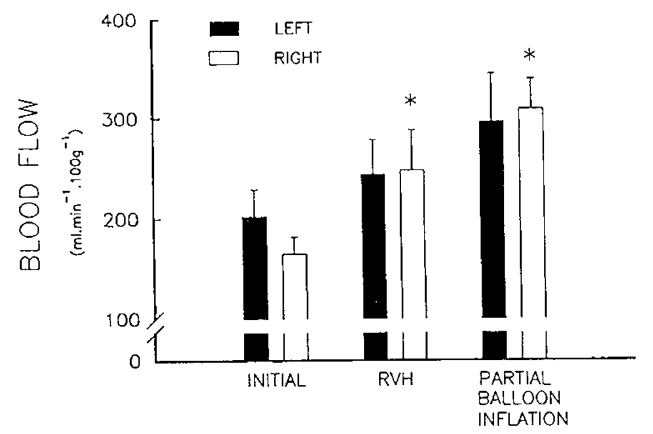

Fig. 7. Myocardial blood flow to the right and left ventricular free wall. ${ }^{*} p<0.01$ as compared with the respective initial values by analysis of variance $(n=6)$.

values $(p<0.01)$. No further significant change in cerebral blood flow with aortic balloon inflation was observed (Fig. 6).

Myocardial blood flow to the free wall of the right ventricle significantly increased with RVH $(p<0.01)$, but did not further change during partial balloon inflation. Left ventricular free-wall blood flow tended to increase during RVH and with aortic balloon inflation but neither change achieved statistical significance (Fig. 7).

To validate the systemic blood flow as calculated from the $\dot{Q}_{\mathrm{P}}$ and shunt fraction equation, we compared the measured values in the six animals into which radiolabeled microspheres were injected with the respective calculated $\dot{Q}_{s}$. No statistically significant difference was observed by paired $t$ test, and the percentage difference between methods was $6.4 \pm 6.1 \%$.

\section{DISCUSSION}

We have shown that an elevation in $\mathrm{P}_{\mathrm{SA}}$ brought about by inflation of an aortic balloon improves oxygenation in the 1-dold pig with RVH. The observed improvement in arterial oxygenation was related to an increase in $\dot{Q}_{\mathrm{P}}$, together with a reduction in foramen ovale right to left shunt.

It is unlikely that factors other than the aortic balloon inflation resulted in the observed increase in arterial $\mathrm{PaO}_{2}$ in our study. The reduction in $\dot{\mathrm{Q}}_{\mathrm{P}}$ and $\mathrm{PaO}_{2}$ and consequent increase in the $\mathrm{Q}_{\mathrm{S}} / \mathrm{Q}_{\mathrm{T}}$ were seen immediately after induction of $\mathrm{RVH}$. These changes were partially reversed with aortic balloon inflation, and although RVH was maintained, deflation of the balloon promptly lowered the $\mathrm{PaO}_{2}$ to the preinflation levels. Lastly, the release of the pulmonary artery occluder was associated with final central hemodynamic, arterial blood gas, and $\mathrm{pH}$ values comparable to the initial ones, suggesting that the decreased $\dot{Q}_{\mathrm{P}}$ and the observed right to left foramen ovale shunt during $\mathrm{RVH}$ was solely responsible for the initial decrease in $\mathrm{PaO}_{2}$.

Our data support the suggestion of Meadow et al. (3) that an increase in $\mathrm{P}_{\mathrm{SA}}$ can lead to reversal of right to left shunting in the newborn with pulmonary arterial hypertension. It is clear from our data that an increase in $\mathrm{P}_{\mathrm{SA}}$ induced partial reversal of the foramen ovale shunt in all animals as evidenced by the significant increase in $\mathrm{PaO}_{2}$. In nine of the 13 animals, aortic balloon inflation also increased the $\dot{\mathrm{DO}}_{2}$, in large part by augmenting $\dot{\mathrm{Q}}_{\mathrm{P}}$. In the other four animals, despite the increase in arterial $\mathrm{O}_{2}$ content, the decrease in $\dot{Q}_{s}$ associated with the reduction in foramen ovale shunt resulted in no change or a decrease in $\mathrm{DO}_{2}$. Thus, the increase in $\mathrm{P}_{\mathrm{SA}}$ brought about by the inflation of the aortic balloon has two distinct effects upon the arterial oxygenation during RVH: 1 ) a decrease in foramen ovale right to left shunt; and 2) an increase in Q $\dot{Q}_{p}$. In the absence of hypoxemia, a partial reversal of foramen ovale shunt leading to an increase in $\mathrm{PaO}_{2}$ has no effect upon $\dot{\mathrm{DO}}_{2}$.

The observed increase in mean systemic oxygen delivery in our study was only partly explained by improved arterial oxygenation due to reduced intracardiac shunt. The more important factor was increased pulmonary (and systemic) blood flow. Because balloon inflation clearly increased systemic vascular resistance and did not alter pulmonary vascular resistance, reduced afterload to either ventricle cannot be implicated as a cause of increased $\dot{Q}_{\mathrm{p}}$. Therefore, the increase in $\dot{\mathrm{Q}}_{\mathrm{P}}$ implies either improved right ventricular performance or an increase in right ventricular preload.

One potential mechanism to explain improved right ventricular performance with increased $\mathrm{P}_{\mathrm{SA}}$ is enhanced myocardial blood flow due to increased coronary artery perfusion pressure. In adult dogs, pulmonary embolism-induced RVH is associated with a decrease in cardiac output (4). Myocardial ischemia secondary to a decrease in coronary blood flow to the right ventricular free wall has been implicated as a contributing cause of the decrease in $\dot{Q}_{P}$ in this model. Further, an increase in $P_{S A}$ has been shown to lead to an increase in cardiac output in adult animals with RVH $(4,5)$, likely as a result of reestablishment of adequate right ventricular coronary perfusion compromised by the increase in right ventricular intracavitary pressure (4). However, in our newborn pig model of RVH, myocardial blood flow to the right ventricular free wall is actually increased much above baseline values (2). In addition, although $\mathrm{Q}_{\mathrm{p}}$ increased along with increasing $\mathrm{P}_{\mathrm{SA}}$, and this was associated with a $20 \%$ increase in mean right ventricular myocardial blood flow, this increase in coronary blood flow did not achieve statistical significance and changes in myocardial flow did not correlate with changes in Q $\dot{Q}_{\mathrm{p}}$. These data do not, therefore, support relief of right ventricular myocardial ischemia as the sole mechanism of improved $\dot{Q}_{\mathrm{P}}$ in this model. However, because direct measurements of myocardial $\mathrm{O}_{2}$ use were not made, this cannot be entirely excluded, nor can we exclude improved myocardial performance related to factors other than ischemia.

An alternate explanation for the increase in $\dot{Q}_{\mathrm{P}}$ during balloon inflation is that reduced foramen ovale right to left shunt leads to an increase in right ventricular preload. Although the absence of a significant increase in $\mathrm{P}_{\mathrm{RA}}$ with inflation of the aortic balloon does not support this hypothesis, this possibility cannot be excluded.

In our preparation, the pericardium was left open, thus allowing for an increase in right ventricular wall compliance. Inasmuch as we did not measure the right ventricular end-diastolic volume, it is possible that preload to the right ventricle was in fact increased but, because of the greater right ventricular compliance, a significant change in $\mathrm{P}_{\mathrm{RA}}$ was not observed.

Although an elevation in $\mathrm{P}_{\mathrm{SA}}$ improved oxygenation in the piglet with RVH, and thus could conceivably have a role in the clinical management of infants with PPHN, our animal data suggest that the present experimental approach is ill suited for this purpose. In our experiment, the improvement in arterial oxygenation with RVH was only observed after a $50 \%$ increase in systemic vascular resistance (partial aortic balloon inflation). Further, in our model, RVH is already associated with a significant reduction in renal and bowel flow. Partial inflation of an aortic balloon in the piglet reduced the blood flow to organs distal to it by $50 \%$, potentially leading to irreversible tissue hypoxic ischemia. A pharmacologic approach to achieving an elevation of $\mathrm{P}_{\mathrm{SA}}$ would seem more reasonable for the purpose. There is one anecdotal report of a significant improvement in arterial oxygenation after epinephrine administration in infants with PPHN (7). However this approach has not yet been systematically investigated. The data of Meadow et al. (3) for the newborn pig suggest that large doses are necessary to accomplish a significant increase in systemic vascular resistance. In their study, a significant increase in $\dot{Q}_{\mathrm{p}}$ was observed during administration of as much as $15 \mu \mathrm{g} / \mathrm{kg} / \mathrm{min}$ of epinephrine, a dose much greater than presently recommended for use in newborn infants (8).

Although this protocol intended to address a common clinical problem related to infants with PPHN, namely right to left foramen ovale shunt, it should be pointed out that our model 
does not mimic other features of this syndrome. The ductus arteriosus, a common site of right to left shunt in infants with PPHN, was ligated in our protocol, and the hemodynamic changes associated with ductus arteriosus shunt and aortic balloon inflation during RVH could not be evaluated. Also, infants with PPHN often have a significant degree of myocardial dysfunction secondary to perinatal hypoxic ischemia $(7,9)$, which might make them less tolerant to an increase in left ventricular afterload.

Nevertheless, we have demonstrated that in the newborn pig with RVH-induced right to left foramen ovale shunt, an elevation in $\mathrm{P}_{\mathrm{SA}}$ can improve systemic oxygenation by increasing $\dot{\mathrm{Q}}_{\mathrm{P}}$ and reducing the shunt fraction. The possibility that a controlled increase in $\mathrm{P}_{\mathrm{SA}}$ might improve oxygenation in infants with hypoxemia due to right to left shunt through fetal channels deserves further study.

\section{REFERENCES}

1. Belik J, Light RB 1989 Effect of increased afterload on right ventricular function in the newborn pig. J Appl Physiol 66:868-869
2. Belik J, Baron K, Light RB 1989 Central hemodynamic and regional blood flow changes in the newborn with right ventricular hypertension. Pediatr Res 26:548-553

3. Meadow WL, Rudinski BF, Strates E 1986 Selective elevation of systemic blood pressure by epinephrine during sepsis-induced pulmonary hypertension in piglets. Pediatr Res 20:872-875

4. Vlahakes GJ, Turley K, Hoffman JIE 1981 The pathophysiology of failure in acute right ventricular hypertension: hemodynamic and biochemical correlations. Circulation 63:87-95

5. Spotnitz HM, Berman MA, Epstein SE 1971 Pathophysiology and experimental treatment of acute pulmonary embolism. Am Heart J 82:511-520

6. Stein PD, Alshabkhoun S, Hawkins HF, Hyland JW, Jarrett CE 1969 Right coronary blood flow in acute pulmonary embolism. Am Heart $J$ 77:356362

7. Riemenschneider TA, Nielsen HC, Ruttenberg HD, Jaffe RB 1976 Disturbances of the transitional circulation: spectrum of pulmonary hypertension and myocardial dysfunction. J Pediatr 89:622-625

8. Kelley SR, Bohn DJ 1988 The use of inotropic and afterload-reducing agents in neonates. Clin Perinatol 15:467-489

9. Walther FJ, Siassi B, Ramadan NA, Wu PY-K 1985 Cardiac output in newborn infants with transient myocardial dysfunction. J Pediatr 107:781-785 